\title{
Longitudinal development of a substorm brightening arc
}

\author{
K. Shiokawa ${ }^{1}$, A. Ieda ${ }^{1}$, A. Nakajima ${ }^{1}$, K. Sakaguchi ${ }^{1}$, R. Nomura ${ }^{1}$, T. Aslaksen ${ }^{2}$, M. Greffen ${ }^{3}$, E. Spanswick ${ }^{3}$, \\ E. Donovan ${ }^{3}$, S. B. Mende ${ }^{4}$, J. McFadden ${ }^{4}$, K.-H. Glassmeier ${ }^{5,6}$, V. Angelopoulos ${ }^{7}$, and Y. Miyashita ${ }^{8}$ \\ ${ }^{1}$ Solar-Terrestrial Environment Laboratory, Nagoya University, Nagoya, Japan \\ ${ }^{2}$ Department of Physics and Technology, University of Troms $\varnothing$, Troms $\varnothing$, Norway \\ ${ }^{3}$ Department of Physics and Astronomy, University of Calgary, Calgary, Canada \\ ${ }^{4}$ Space Science Laboratory, University of California Berkeley, CA, USA \\ ${ }^{5}$ Institut of Geopyhsics and extraterrtestrial Physics, TU Braunschweig, Germany \\ ${ }^{6}$ Max Planck Institut of Solar System Reserach, Katlenburg-Lindau, Germany \\ ${ }^{7}$ Institute of Geophysics and Planetary Physics, University of California at Los Angeles, Los Angeles, CA, USA \\ ${ }^{8}$ Institute of Space and Astronautical Science, Japan Aerospace Exploration Agency, Sagamihara, Japan
}

Received: 7 October 2008 - Revised: 26 February 2009 - Accepted: 8 April 2009 - Published: 4 May 2009

\begin{abstract}
We present simultaneous THEMIS-ground observations of longitudinal (eastward) extension of a substorm initial-brightening arc at Gillam (magnetic latitude: $65.6^{\circ}$ ) at 08:13 UT on 10 January 2008 . The speed of the eastward arc extension was $\sim 2.7 \mathrm{~km} / \mathrm{s}$. The extension took place very close to the footprints of the longitudinally separated THEMIS E and D satellites at $\sim 12 R_{E}$. The THEMIS satellites observed field dipolarization, weak earthward flow, and pressure increase, which propagated eastward from $\mathrm{E}$ to $\mathrm{D}$ at a speed of $\sim 50 \mathrm{~km} / \mathrm{s}$. The THEMIS A satellite, located at $1.6 R_{E}$ earthward of THEMIS E, observed fluctuating magnetic field during and after the dipolarization. The THEMIS E/D observations suggest that the longitudinal extension of the brightening arc at substorm onset is caused by earthward flow braking processes which produce field dipolarization and pressure increase propagating in longitude in the nearearth plasma sheet.
\end{abstract}

Keywords. Magnetospheric physics (Auroral phenomena; Plasma sheet; Storms and substorms)

\section{Introduction}

Substorms are fundamental disturbances in the magnetosphere and the polar ionosphere of Earth, but their onset mechanism is still a matter of some controversy. The auroral substorm originally defined by Akasofu (1964) shows

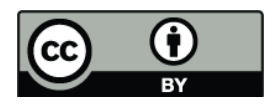

Correspondence to: K. Shiokawa (shiokawa@stelab.nagoya-u.ac.jp) a brightening of an auroral arc in the nightside auroral zone, and this brightening arc might be a manifestation of the processes causing the onset of magnetospheric substorms. The recent development of high-resolution cooled Charge Coupled Devise (CCD) cameras have made it possible to observe small-scale structures of brightening auroral arcs at substorm onset. Donovan et al. (2006a) reported a brightening arc which consisted of beads propagating eastward with a wavelength of $\sim 100 \mathrm{~km}$. Liang et al. (2008) studied eight events of longitudinal wave structures of the brightening arc and concluded that the longitudinal wave number ranges between 100 and 300 (wavelength of $\sim 50-150 \mathrm{~km}$ ). These papers suggest that the observed longitudinal waves correspond to the magnetospheric instabilities which are responsible for the substorm onset in the near-earth plasma sheet.

Liang et al. (2008) also found that the intensification of the brightening arc occurs within $\sim 10$ s over an arc segment extending to approximately $1 \mathrm{~h}$ magnetic local time (longitude). The speed of the longitudinal expansion of the brightening arcs has some implications for the investigation of the onset mechanism. In the relevant literature, the speed varies from $1 \mathrm{~km} / \mathrm{s}$ to more than $10 \mathrm{~km} / \mathrm{s}$ (e.g., Solovyev et al., 1997; Yago et al., 2005, 2007; Shiokawa et al., 2005; Sakaguchi et al., 2009). Angelopoulos et al. (2008) reported the simultaneous observation of a westward traveling surge (westward speed of $1 \mathrm{MLT} / \mathrm{min} \sim 14 \mathrm{~km} / \mathrm{s}$ ) with the THEMIS satellite in the source plasma sheet. However, it is necessary to perform more simultaneous observations of the longitudinal development of brightening arcs using ground observatories and magnetospheric satellites since there are few examples of such observations.

Published by Copernicus Publications on behalf of the European Geosciences Union. 


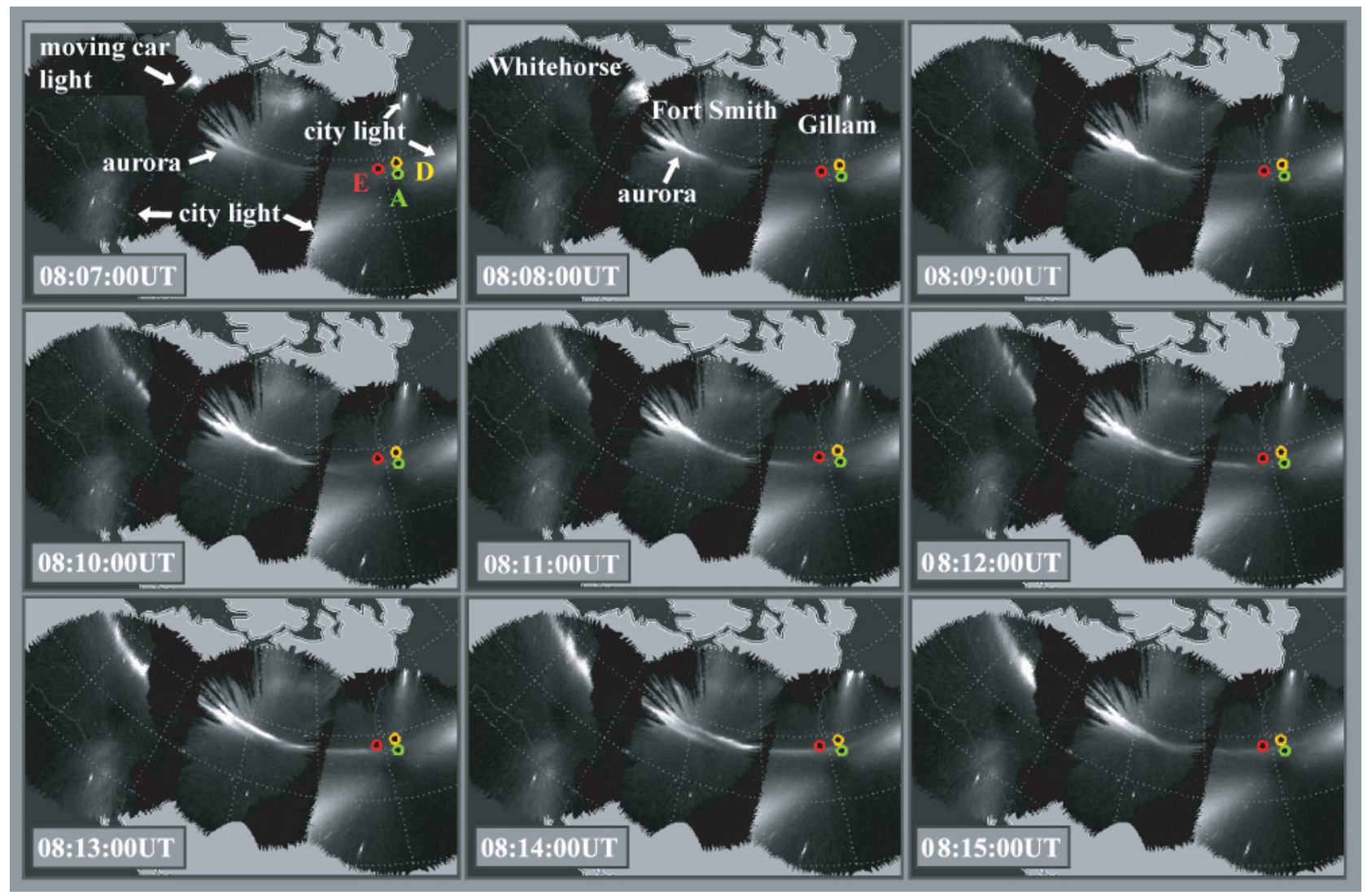

Fig. 1. Mosaic auroral images showing the auroral brightening at the substorm onset, which were obtained at three THEMIS all-sky imaging stations (from left to right, Whitehorse, Fort Smith, and Gillam) at 1-min intervals between 08:07:00 UT and 08:15:00 UT on 10 January 2008. Yellow, red, and green circles indicate the footprints of THEMIS D $\left(58.7^{\circ} \mathrm{N}, 267.1^{\circ} \mathrm{E}\right), \mathrm{E}\left(58.7^{\circ} \mathrm{N}, 264.3^{\circ} \mathrm{E}\right)$, and $^{\mathrm{A}}\left(57.8^{\circ} \mathrm{N}\right.$, $\left.267.3^{\circ} \mathrm{E}\right)$, respectively.

During 2-15 January 2008, we made THEMIS-ground campaign observations at two auroral-zone stations in Canada. Two 30-Hz sampling all-sky TV cameras (Shiokawa et al., 1996) and two $\sim 1$-s sampling narrow field-of-view $(\mathrm{FoV})$ cameras were installed at Gillam $\left(56.4^{\circ} \mathrm{N}, 265.4^{\circ} \mathrm{E}\right.$, dipole geomagnetic latitude (MLAT): $65.6^{\circ}$ ) and Fort Smith $\left(60.0^{\circ} \mathrm{N}, 248.1^{\circ} \mathrm{E}\right.$, MLAT: $\left.67.0^{\circ}\right)$. As an initial result of the campaign, we present observations of a longitudinally extending brightening arc performed simultaneously on the ground and by the longitudinally separated THEMIS satellites in the near-earth plasma sheet.

\section{Observations}

During the campaign period of 2-15 January, the THEMIS satellite was above the Canadian sector at postmidnight local times, while the substorm brightenings most frequently started in the premidnight sector. This configuration allowed for the longitudinal development of the brightening arcs at substorm onset to be observed both on ground and with the THEMIS satellites. In this paper, we focus on one such event observed on 10 January 2008. Although the event was first identified using our 30-Hz all-sky TV camera at Gillam, in this paper we use auroral images from the THEMIS allsky imager (ASI) array, which has a sampling period of $3 \mathrm{~s}$ (Donovan et al., 2006b; Mende et al., 2008), since the development of the brightening arc was rather slow at Gillam while the THEMIS ASI array provided a wider view of the auroral development over the central and the eastern parts of Canada.

Figure 1 shows mosaic auroral images taken at 08:0708:15 UT (01:47-01:55 LT at Gillam) at 1-min intervals at Whitehorse (left), Fort Smith (center), and Gillam (right) on 10 January 2008 during an auroral brightening event. The footprints of THEMIS A, D, and E are shown with green, yellow, and red circles, respectively. These footprints were calculated for the respective locations of the satellites at 08:10 UT by using the Tsyganenko-96 geomagnetic field model (Tsyganenko, 1995). Ambiguities of a few degrees in latitude are expected from the field-line mapping at different interplanetary parameters. The effect of field-aligned current may cause longitudinal shift of the footprint (e.g., Donovan, 1993; Donovan et al., 2008). 


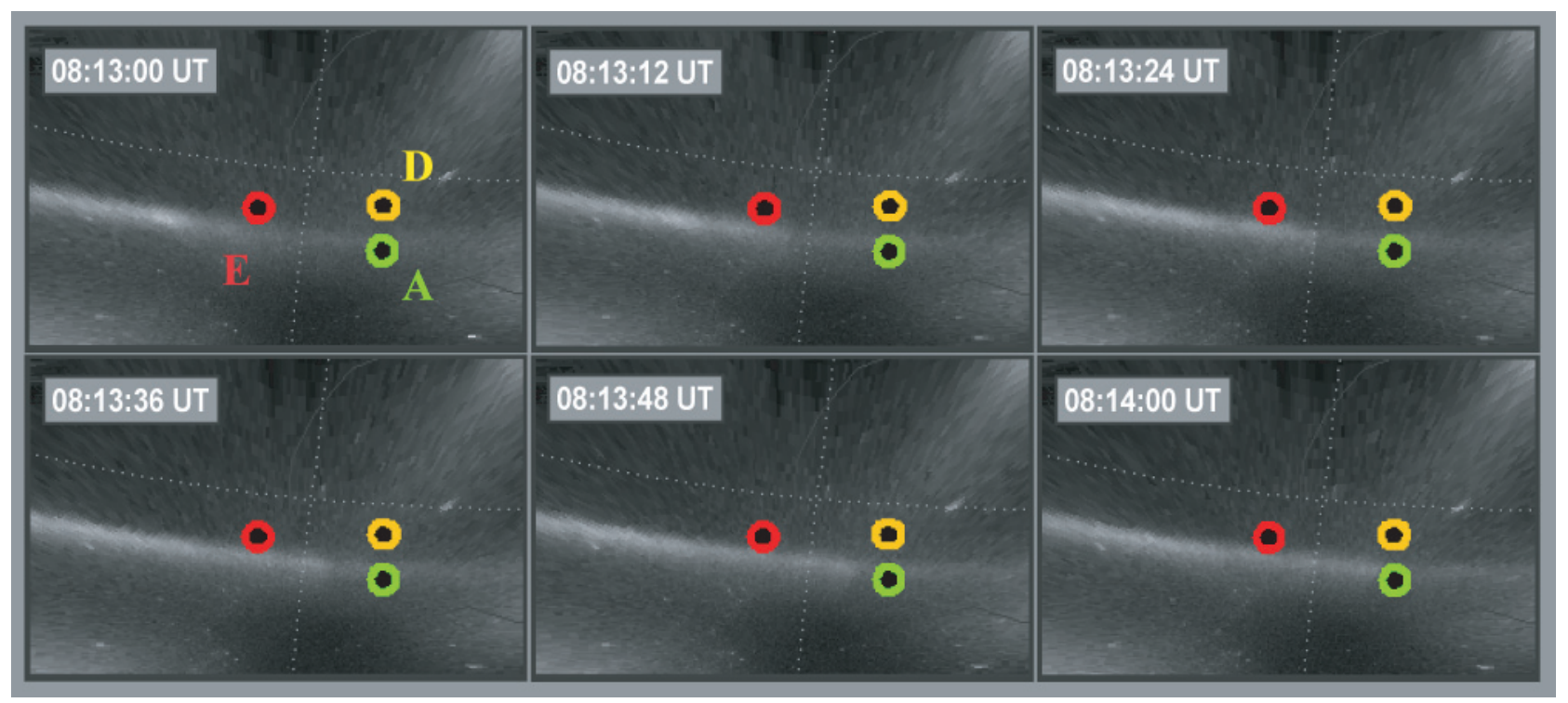

Fig. 2. Auroral images expanded from Fig. 1 in the vicinity of the footprints of THEMIS D (yellow), E (red), and A (green) at 08:13:0008:14:00 UT on 10 January 2008.

The auroral brightening event occurred at Fort Smith at 08:08:00 UT, after which it immediately extended westward toward Whitehorse at 08:09:00-08:10:00 UT. On the other hand, the eastward extension toward Gillam was much slower, lasting from 08:10:00 UT to 08:14:00 UT. The arc extending eastward reached the footprint of THEMIS E (red circle) at $\sim 08: 13: 00$ UT and of THEMIS D (yellow circle) at $\sim 08: 14: 00$ UT. After 08:15:00 UT, the extension of this arc ceased, and it did not develop further on a global scale. The AL index calculated from the THEMIS GBO magnetometers decreased by $\sim 70 \mathrm{nT}$ between 08:06 UT and 08:14 UT. Coherent Pi2 pulsations and a weak positive bay (a few nT) were observed starting at 08:05 UT at the low-latitude THEMIS GBO magnetometers in North America.

Figure 2 shows auroral images corresponding to the areas near the THEMIS footprints at 08:13:00-08:14:00 UT expanded from Fig. 1. Although the eastward edge of the arc extending eastward was not clearly defined, the arc reached the THEMIS E footprint (red circle) at $\sim 08: 13: 00 \mathrm{UT}$ and the THEMIS D footprint (yellow circle) at 08:14:00 UT. Since the separation of the two footprints was $162 \mathrm{~km}$, the velocity of the eastward extension was estimated to be $\sim 2.7 \mathrm{~km} / \mathrm{s}$ $(=162 \mathrm{~km} / 60 \mathrm{~s})$.

Figure 3 shows the locations of the THEMIS A, D, and E satellites in GSM coordinates at 08:10 UT on 10 January 2008. The THEMIS E and D satellites were at nearly the same $\mathrm{X}$ and $\mathrm{Z}$ location, being separated by $\sim 1 R_{E}$ only in $Y_{\mathrm{GSM}}$ direction at a radial distance of $\sim 12 R_{E}$. THEMIS A was $\sim 1.6 R_{E}$ earthward of THEMIS $\mathrm{E}$ at a radial distance of $\sim 9.9 R_{E}$. Note that at the ionospheric altitude, THEMIS A (green) was at the same longitude as THEMIS D (yellow). Thus, the brightening arc extension from THEMIS E toward

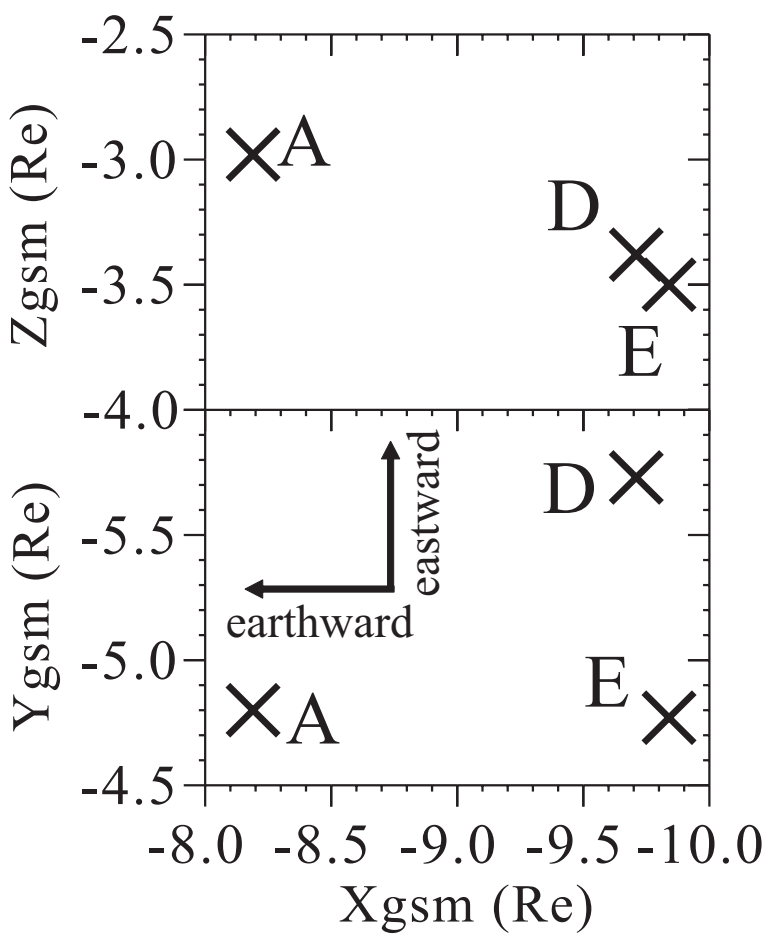

Fig. 3. Locations of the THEMIS A $(-8.2,-4.8,-3.0)$, D (-9.7, $-5.7,-3.4)$, and $\mathrm{E}(-9.8,-4.8,-3.5)$ satellites in the GSM coordinates at 08:10 UT on 10 January 2008.

THEMIS A/D in Figs. 1 and 2 maps to the eastward (minus $Y_{\mathrm{GSM}}$ ) and earthward (plus $X_{\mathrm{GSM}}$ ) propagation of some corresponding structure in the magnetosphere in the bottom panel of Fig. 3. 


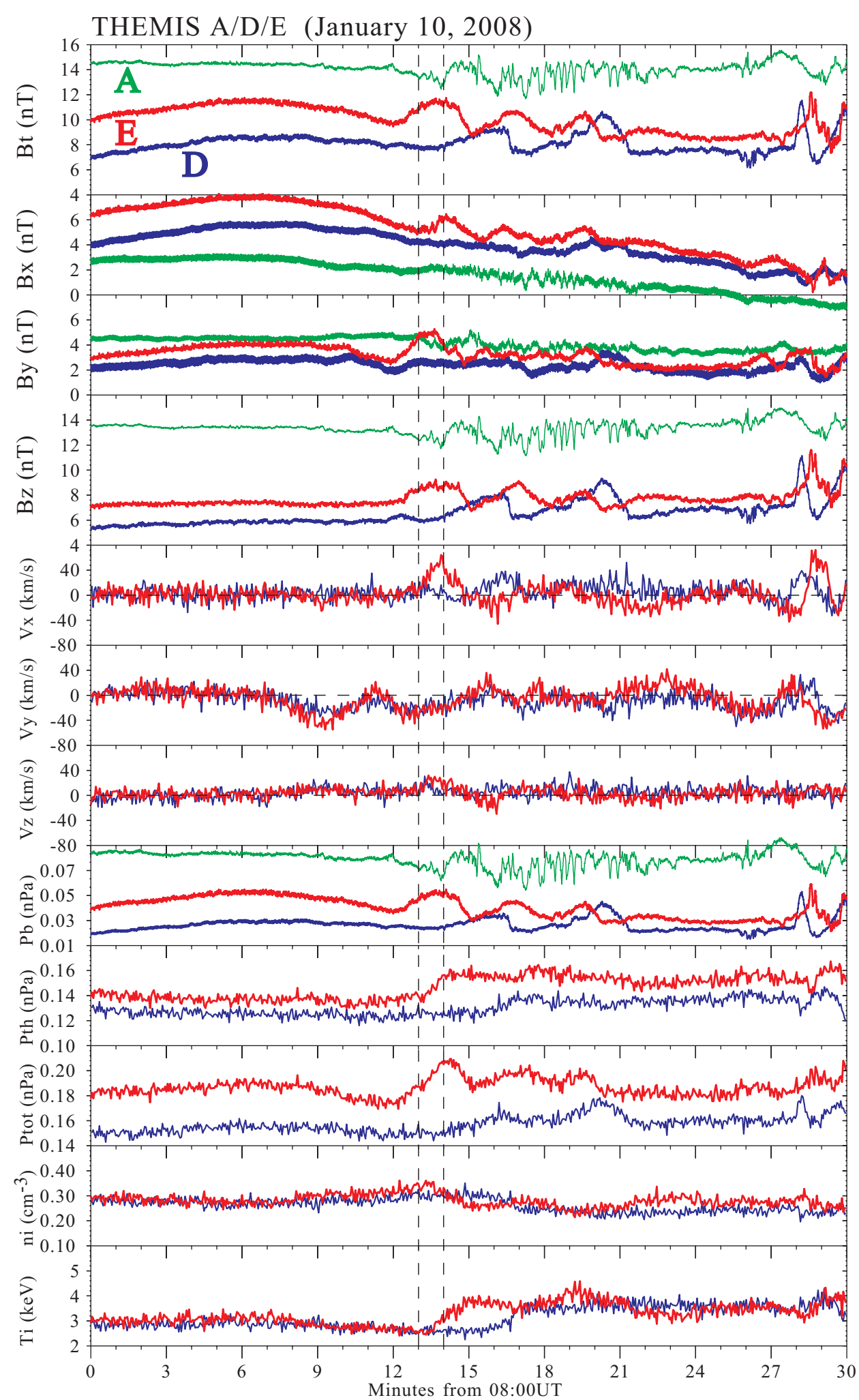

Fig. 4. Magnetic field, bulk flow velocity, magnetic, thermal, and total pressures, and ion density and temperature as obtained by the THEMIS A (green), D (blue), and E (red) satellites at 08:00-08:30 UT on 10 January 2008. The magnetic field and the flow velocities are in GSM coordinates. Only the magnetic field data were available for THEMIS A. 
Figure 4 represents the magnetic field, the bulk flow velocity, the magnetic and thermal pressures, and the ion density and temperature as observed by the THEMIS E (red), D (blue), and A (green) satellites at 08:00-08:30 UT on 10 January 2008. The data regarding the magnetic field and the plasma were obtained with the fluxgate magnetometer (FGM) (Auster et al., 2008) and with the electrostatic analyzer (ESA) (McFadden et al., 2008), respectively. In this regard, the ESA data from THEMIS A were not available for the plotted interval. The vertical dashed lines at 08:13:00 UT and 08:14:00 UT indicate the timings when the arc extending eastward reached the footprints of THEMIS E and D, respectively.

Since the $B_{x}$ and $B_{z}$ intensities are comparable, and since the thermal pressure is much larger than the magnetic pressure $(\beta>1)$, the THEMIS E and D satellites were located in the plasma sheet near the equatorial plane. Furthermore, $B_{z}$ is the major component for THEMIS A, indicating that THEMIS A was also near the magnetospheric equatorial plane. Note that $B_{x}$ decreases for all satellites and finally reverses its sign at $\sim 08: 30 \mathrm{UT}$, indicating a northward motion of the magnetosphere. This motion starts around the same time as the velocity perturbations at $\sim 08: 06 \mathrm{UT}$.

About 1 min before the arc reached its footprint, THEMIS E observed a field dipolarization (an increase in both $B_{z}$ and $\left.B_{\text {total }}\right)$, and a weak earthward flow with a peak of $\sim 50 \mathrm{~km} / \mathrm{s}$ starting at 08:12:00 UT. This timing difference of $1 \mathrm{~min}$ might be due to the Alfvén transit time from the magnetosphere to the ionosphere. The magnetic pressure $P_{b}$ increased at this time, and the thermal pressure $P_{t h}$ and the total pressure $P_{\text {tot }}=P_{b}+P_{t h}$ also increased at 08:12:00-08:13:00 UT and maintained high values throughout the plotted interval. Similar features of field dipolarization, weak earthward flow, and increase in magnetic and thermal pressures were observed with THEMIS D starting at $\sim 08: 14: 00 \mathrm{UT}$, with a more gradual trend. If we take the timing difference of 2 min between THEMIS E and D into account, the $1-R_{E}$ difference of these two satellites gives an eastward propagation speed of $\sim 50 \mathrm{~km} / \mathrm{s}$. The magnetic field data of THEMIS A show a local dipolarization at 08:14:00 UT, nearly simultaneously with THEMIS E. Then, the magnetic field fluctuates rapidly on a time scale of the order of $10 \mathrm{~s}$.

\section{Summary and discussion}

In this paper, we report simultaneous observations of a longitudinal (eastward) extension of a brightening arc at substorm onset at 01:50LT on 10 January 2008, both on the ground and by the THEMIS A, D, and E satellites. We found that the magnetospheric source region of the brightening arcs extending eastward at THEMIS E and D corresponds to the field dipolarization, the weak earthward flow, and the pressure enhancement, which propagate with a speed of $\sim 50 \mathrm{~km} / \mathrm{s}$ in the magnetosphere at a radial distance of $\sim 12 R_{E}$. THEMIS A at $9.9 R_{E}$ observed a dipolarization, although the magnetic pressure remained the same. Instead, THEMIS A observed a fluctuating magnetic field after the dipolarization.

The features observed by THEMIS E and D are to be expected if the satellites are located just earthward of the flow braking region (Shiokawa et al., 1997, 1998). The braking causes field dipolarization earthward of the braking region through the dawnward inertia current. The earthward compression of the field and the pileup of the dipolar field carried by the earthward flow also cause field dipolarization and enhancement of the magnetic pressure. The earthward injection of plasma causes the enhancement of the thermal pressure (e.g., Kistler et al., 1992; Miyashita et al., 2009). Thus, the present observations suggest that the brightening aurora extending in longitudinal direction was caused by the earthward flow and its subsequent braking.

The speed of the eastward extension as determined by the two THEMIS satellites was $\sim 50 \mathrm{~km} / \mathrm{s}$. This velocity is much slower than the local Alfvén velocity $(\sim 400 \mathrm{~km} / \mathrm{s}$ for a density of $0.3 \mathrm{~cm}^{-3}$ and a magnetic field of $10 \mathrm{nT}$ during the event on 10 January 2008), and is of the same order as the observed bulk flow velocity. This fact is also consistent with the idea that the flow braking caused the observed longitudinal extension of the brightening arc. However, we can not distinguish whether the braking occurs sequentially from the THEMIS E longitude to the THEMIS D longitude, or the observed weak eastward flow $(\sim 20 \mathrm{~km} / \mathrm{s})$ during and before the dipolarization at THEMIS E corresponds to the change of the flow direction from earthward to eastward caused by the braking.

It is interesting to note that during the first dipolarization at 08:12 UT, the THEMIS E observed a concurrent increase in $B_{y}$ component. This may imply tailward current generation associated with a development of azimuthal (westward) pressure gradient. Such a development of westward pressure gradient is seen by comparing the pressures observed by THEMIS E and D at 08:12 UT.

It should be noted that the present observation does not separate the two substorm onset models, i.e., the reconnection at $20-30 R_{E}$ (outside-in model) and the current disruption/pressure reduction processes at $\sim 10 R_{E}$ (inside-out model), because both processes generate earthward flows and their respective braking in the near-earth plasma sheet. The fluctuating magnetic field observed by THEMIS A might be an indication of current-driven instability which causes the tail current disruption at substorm onset (e.g., Lui et al., 1992), although the amplitude of the fluctuation is smaller than the intensity of the ambient field. It is interesting that THEMIS A observed the fluctuations at $9.9 R_{E}$ while THEMIS E and D at $\sim 12 R_{E}$ did not. This suggests that the current disruption and the associated rarefaction occurring near THEMIS A caused the earthward flow and its braking at THEMIS D/E, although the maximum amplitude of the fluctuation was observed after the dipolarization. 
Acknowledgements. The observatories at Gillam and Fort Smith are Canadian Geospace Monitoring (CGSM) program core sites operated by the Canadian Space Agency. The campaign was carried out by the Solar-Terrestrial Environment Laboratory, Nagoya University in collaboration with the Canadian Space Agency, and with the support from the NORSTAR team of the University of Calgary. THEMIS is supported under NASA NAS5-02099. The THEMIS GBO magnetometers were used for identifying the low-latitude Pi2 and the positive $\mathrm{H}$ bay signatures. Financial support for the work of KHG by the German Ministerium für Wirtschaft und Technologie and the Deutsches Zentrum für Luft- und Raumfahrt under grant 50QP0402 is acknowledged. This work was supported by a Grantin-Aid for Scientific Research (19403010) of the Ministry of Education, Culture, Sports, Science, and Technology of Japan.

Topical Editor R. Nakamura thanks J. Liang and another anonymous referee for their help in evaluating this paper.

\section{References}

Akasofu, S. I.: The development of the auroral substorm, Planet Space Sci., 12, 273-282, 1964.

Angelopoulos, V., Sibeck, D., Carlson, C. W., et al.: First Results from the THEMIS Mission, Space Sci. Rev., 141, 453-476, doi:10.1007/s11214-008-9378-4, 2008.

Auster, H. U., Glassmeier, K. H., Magnes, W., et al.: The THEMIS fluxgate magnetometer, Space Sci. Rev., 141, 235-264, doi:10.1007/s11214-008-9365-9, 2008.

Donovan, E.: Modeling the magnetic effects of field-aligned currents, J. Geophys. Res., 98, 13529-13543, 1993.

Donovan, E., Mende, S. B., Jackel, B., Syrjäsuo, M., Meurant, M., Voronkov, I., Frey, H. U., Angelopoulos, V., and Connors, M.: The azimuthal evolution of the substorm expansive phase onset aurora, Proc. of International Conference on Substorms-8, edited by: Syrjäsuo, M. and Donovan, E., Univ. of Calgary, pp. 55-60, 2006a.

Donovan, E., Mende, S., Jackel, B., et al.: The THEMIS all-sky imaging array-system design and initial results from the prototype imager, J. Atmos. Sol. Terr. Phys., 68, 1472-1487, 2006b.

Donovan, E., Liu, W., Liang, J., et al.: Simultaneous THEMIS in situ and auroral observations of a small substorm, Geophys. Res. Lett., 35, L17S18, doi:10.1029/2008GL033794, 2008.

Kistler, L. M., Mobius, E., Baumjohann, W., Paschmann, G., and Hamilton, D. C.: Pressure Changes in the Plasma Sheet During Substorm Injections, J. Geophys. Res., 97(A3), 2973-2983, 1992.

Lui, A. T. Y., Lopez, R. E., Anderson, B. J., Takahashi, K., Zanetti, L. J., McEntire, R. W., Potemra, T. A., Klumpar, D. M., Greene, E. M., and Strangeway, R.: Current disruptions in the near-Earth neutral sheet region, J. Geophys. Res., 97, 1461-1480, 1992.

McFadden, J. P., Carlson, C. W., Larson, D., Angelopoulos, V., Ludlam, M., Abiad, R., Elliott, B., Turin, P., and Marckwordt, M.: The THEMIS ESA plasma instrument and in-flight calibration, Space Sci. Rev., 141, 277-302, doi:10.1007/s11214-008-94402, 2008.
Liang, J., Donovan, E. F., Liu, W. W., Jackel, B., Syrjäsuo, M., Mende, S. B., Frey, H. U., Angelopoulos, V., and Connors, M.: Intensification of preexisting auroral arc at substorm expansion phase onset: Wave-like disruption during the first tens of seconds, Geophys. Res. Lett., 35, L17S19, doi:10.1029/2008GL033666, 2008.

Mende, S. B., Harris, S. E., Frey, H. U., Angelopoulos, V., Russell, C. T., Donovan, E., Jackel, B., Greffen, M., and Peticolas, L. M.: The THEMIS array of ground based observatories for the study of auroral substorms, Space Sci. Rev., 141, 357-387, doi:10.1007/s11214-008-9380, 2008.

Miyashita, Y., Machida, S., Kamide, Y., et al.: A state-of-art picture of substorm-associated evolution of the near-Earth magnetotail obtained from superposed epoch analysis, J. Geophys. Res., 114, A01211, doi:10.1029/2008JA013225, 2009.

Russell, C. T., Chi, P. J., Dearborn, D. J., Ge, Y. S., Kuo-Tiong, B., Means, J. D., Pierce, D. R., Rowe, K. M., and Snare, R. C.: THEMIS ground-based magnetometers, Space Sci. Rev., 141, 389-412, doi:10.1007/s11214-008-9337-0, 2008.

Sakaguchi, K., Shiokawa, K., Ieda, A., Nomura, R., Nakajima, A., Greffen, M., Donovan, E., Mann, I. R., Kim, H., and Lessard, M.: Fine structures and dynamics in auroral initial brightening at substorm onsets, Ann. Geophys., 27, 623-630, 2009, http://www.ann-geophys.net/27/623/2009/.

Shiokawa, K., Yumoto, K., Tanaka, Y., et al.: Auroral observations using automatic optical instruments: relations with multiple Pi 2 magnetic pulsations, J. Geomag. Geoelectr., 48, 1407-1419, 1996.

Shiokawa, K., Baumjohann, W., and Haerendel, G.: Braking of high-speed flows in the near-Earth tail, Geophys. Res. Lett., 24, 1179-1182, 1997.

Shiokawa, K., Baumjohann, W., Haerendel, G., et al.: High-speed ion flow, substorm current wedge, and multiple Pi 2 pulsations, J. Geophys. Res., 103, 4491-4508, 1998.

Shiokawa, K., Yago, K., Yumoto, K., Baishev, D. G., Solovyev, S. I., Rich, F. J., and Mende, S. B.: Ground and satellite observations of substorm onset arcs, J. Geophys. Res., 110, A12225, doi:10.1029/2005JA011281, 2005.

Solovyev, S. I., Yumoto, K., Baishev, D. G., and Molochushkin, N. E.: Generation and spectrum formation of high-latitude Pi2 geomagnetic pulsations during pseudobreakups and multiple substorm onsets, Geomagnetism Aeronomy, 37(5), 579-586, 1997.

Tsyganenko, N. A.: Modeling the Earth's magnetospheric magnetic field confined within a realistic magnetopause, J. Geophys. Res., 100(A4), 5599-5612, 1995.

Yago, K., Shiokawa, K., Hayashi, K., and Yumoto, K.: Auroral particles associated with a substorm brightening arc, Geophys. Res. Lett., 32, L06104, doi:10.1029/2004GL021894, 2005.

Yago, K., Shiokawa, K., Yumoto, K., Baishev, D. G., Solovyev, S. I., and Rich, F. J.: Simultaneous DMSP, all-sky camera, and IMAGE FUV observations of the brightening arc at a substorm pseudo-breakup, Earth Planets Space, 59, 45-49, 2007. 